\title{
Seismicity in Central North Africa at Low Magnitudes: A First Look at the TAM Event Detected Data Base
}

Phil E. Harben

January, 1997

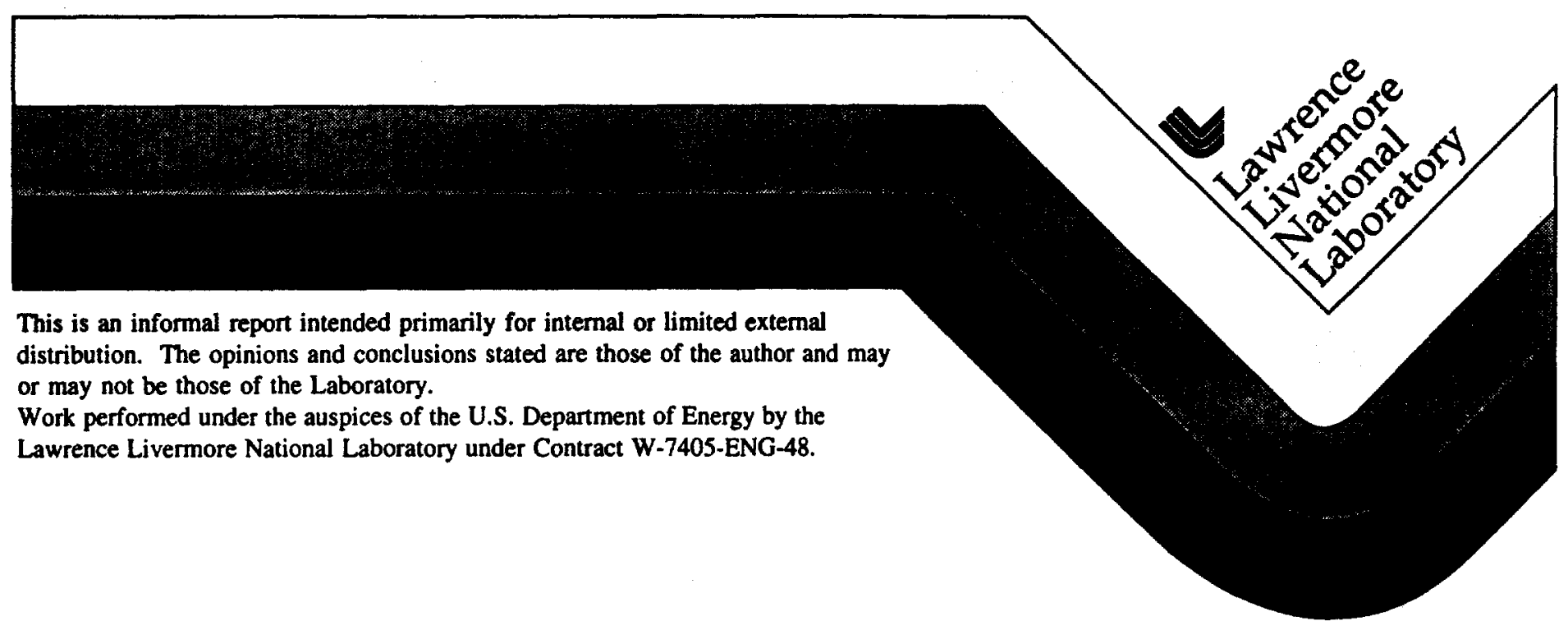




\section{DISCLAIMER}

This document was prepared as an account of work sponsored by an agency of the United States Government. Neither the United States Government nor the University of California nor any of their employees, makes any warranty, express or implied, or assumes any legal liability or responsibility for the accuracy, completeness, or usefulness of any information, apparatus, product, or process disclosed, or represents that its use would not infringe privately owned rights. Reference herein to any specific commercial product, process, or service by trade name, trademark, manufacturer, or otherwise, does not necessarily constitute or imply its endorsement, recommendation, or favoring by the United States Government or the University of California. The views and opinions of authors expressed herein do not necessarily state or reflect those of the United States Government or the University of California, and shall not be used for advertising or product endorsement purposes.

This report has been reproduced directly from the best available copy.

Available to DOE and DOE contractors from the Office of Scientific and Technical Information

P.O. Box 62, Oak Ridge, TN 37831

Prices available from (615) 576-8401, FTS 626-8401

Available to the public from the

National Technical Information Service

U.S. Department of Commerce

5285 Port Royal Rd.,

Springfield, VA 22161 


\title{
Seismicity in Central North Africa At Low Magnitudes: \\ A First Look At the TAM Event Detected Data Base
}

\author{
P.E. Harben
}

Introduction

Teleseismic observations of seismicity in the central North Africa region show that the region is aseismic. This is true for earthquakes with a body wave magnitude greater than about 4 or so. For earthquakes with body wave magnitudes substantially below about 4, the teleseismic observations of seismicity in the central Sahara are incomplete since smaller earthquakes would probably not be detected and located by the current teleseismic monitoring networks. Only one known open seismic station has been operating in the central Sahara. This is the Tamanrasset (TAM) seismic station in southern Algeria. A simple analysis of data records from this station can be used to determine if the central Sahara is also relatively aseismic at magnitudes substantially below 4 . That is the primary purpose of this study.

The TAM seismic station was installed by the French Institute de Physique de Globe under the auspices of the GEOSCOPE program in November, 1983. Data were recorded continuously at a low sample rate until March, 1990 when 20 sample per second event recording was implemented.

The TAM station is located within a large region of precambrian bedrock underlying surface sediments [1]. The station consists of a surface seismic vault with instrumentation mounted on a concrete pier coupled to solid bedrock. The seismic instrumentation deployed consists of a Streckeisen STS1 3-component seismometer modified for very broad band (VBB) recording.

This data report documents initial statistics and conclusions resulting from a first look at the entire event detected data set for this station from March, 1990 to September, 1995. The full data set is now available on the LLNL Treaty Verification Seismic Database. The event detect operational history during this period is shown in Table 1. 
event waveforms were visually inspected in three different passbands:

1) no filtering

2) 4-pole high pass filtering at $1 \mathrm{~Hz}$ corner

3) 4-pole high pass filtering at $2 \mathrm{~Hz}$ corner

All events with essentially no energy above $1 \mathrm{~Hz}$ were rejected as non-regional in nature. Events with S-P times of less than about $230 \mathrm{sec}$ (approximately $1800 \mathrm{~km}$ distant) were considered regional events. Many events could not be located either because of low $\mathrm{S} / \mathrm{N}$ or a bad horizontal component recording (almost always the $\mathrm{E}$ $\mathrm{W}$ component for this station).

\section{First Look Results}

In all, 24 regional events were identified in the entire data set. The events are listed in Table 2 as near-regional, mid-regional, and far-regional. These categories were arbitrarily chosen to be: $0-150 \mathrm{~km}$ from TAM as near-regional, $150 \mathrm{~km}-1000 \mathrm{~km}$ as mid-regional, and over $1000 \mathrm{~km}$ as far-regional. Based on S-P travel time, no mid-regional events were identified and only 6 near-regional events were identified. The 18 far-regional events could all be located by association with events listed in teleseismic catalogues and 3 of the 6 near-regional events were located by back azimuth bearing estimation coupled with distance determination using S-P times. Figure 1 plots all the regional events that were located. Note that many of the plotted locations shown mark two events that were located very close together, probably associated with each other. It should also be noted that the far regional events listed are only a partial set of those that occurred during the time period of this data set. These events were selected to illustrate various regional phase propagation paths to TAM, estimation of far regional seismicity is not a goal of this study.

The TAM station is in relatively close proximity to one major Algerian mine. This is the Timagouine mine located about $160 \mathrm{~km}$ southwest of the TAM station. Timagouine is an underground uranium mine with an estimated maximum routine mining explosive blast size of about one metric ton of ANFO [2]. Since most major Algerian mines are near the coast, some $1500 \mathrm{~km}$ from the TAM station, the possibility of identifying mine blast recordings from Timagouine seemed most likely. Evaluation of the full TAM event data set, however, failed to identify a single event with Timagouine as the likely origin. 
Table 1: TAM Broadband event detect operational history to day 283, 1995

\begin{tabular}{|l|l|}
\hline \multicolumn{1}{|c|}{ Year } & \multicolumn{1}{|c|}{ Operational Periods During Year } \\
\hline \hline 1990 & Days 071-245 \\
\hline 1991 & Days 085-365 \\
\hline 1992 & Days 000-365 \\
\hline 1993 & Days 000-365 \\
\hline 1994 & Days 000-365 \\
\hline 1995 & Days 000-283 \\
\hline
\end{tabular}

The following discussion begins with a short synopsis of the data records, first look methodology, and the triggering algorithm employed at the TAM station. This is followed by details of the first look methodology results; events determined, statistics, locations, and illustrative waveform recordings. Signal-to-noise ratios are compared for three southern Mediterranean events with equal path lengths to TAM and the Sonseca array in Spain. Conclusions on near and mid-regional seismicity as deduced from the TAM event data set and the potential utility such a station for treaty verification monitoring completes the discussion.

\section{$\underline{\text { Recorded Data Features }}$}

An STA/LTA event triggering algorithm is employed at TAM. The total event record length is one hour which includes 30 minutes of pre-event noise. The STA is 2 minutes long, the LTA is 30 minutes long, and the triggering ratio is 2 . All the data, as obtained from the GEOSCOPE open data center, is recorded in velocity and corrected to units of nanometers/sec. This study converts the units to $\mathrm{m} / \mathrm{sec}$ in all waveform figures.

The event data base over the operational period shown in Table 1 consists of 1940 events recorded over a total operational period of 1832 days. The resulting average number of events per day is 1.056 and the average number of 1-hour records per day is 1.2 (note that some events are 2 or 3 hours long).

To determine regional events from the event data set, all three components of the 
The relatively low broadband background noise, simple upper crust geology, and competent bedrock site of TAM results in excellent waveform recordings for many regional events. A selected set of the waveforms are shown in Figures 2-10.

Table 2: Events

\begin{tabular}{|l|l|l|l|}
\hline & \multicolumn{1}{|c|}{ Far regional } & Mid regional & Near regional \\
\hline \hline & 9201920 & & 9014113 \\
\hline & 9207213 & & 9114110 \\
\hline & 9207300 & & 9313706 \\
\hline & 9216419 & & 9327211 \\
\hline & 9217118 & & 9415411 \\
\hline & 9218315 & & 9513504 \\
\hline & 9227315 & & \\
\hline & 9229709 & & \\
\hline & 9230410 & & \\
\hline & 9314307 & & \\
\hline & 9324617 & & \\
\hline & 9325315 & & \\
\hline & 9335714 & & \\
\hline & 9414608 & & \\
\hline & 9415408 & & \\
\hline & 9514223 & & \\
\hline & 9524622 & & \\
\hline \hline Total \# & 9526511 & & \\
\hline & 18 & & \\
\hline
\end{tabular}

\section{Regional Seismicity Near TAM}

Six near-regional events were determined in the data set. Magnitudes were deter- 
mined for the three largest events which, based on S-P time, were all located about $100 \mathrm{~km}$ from TAM. The magnitude of the three largest near-regional events have been calculated in a somewhat arbitrary but consistent way. The velocity waveforms were 4-pole high passed at $0.4 \mathrm{~Hz}$ and the resulting waveform integrated to obtain a seismogram in the displacement units of nanometers. The seismogram was then transformed to produce an equivalent output seismogram from a standard Wood Anderson seismometer. The standard local Richter magnitude was then calculated from the averaged horizontal component waveforms recognizing that the Richter local magnitude was designed for characteristics of local earthquakes in California. The local magnitudes for the three largest events are: $2.7,2.3$, and 1.8. Only the 2.7 and 2.3 magnitude earthquakes triggered the TAM event detect, consequently the TAM event detect threshold for near-regional events about $100 \mathrm{~km}$ away is a Richter magnitude between about 1.8 and 2.3.

We must distinguish between regional events that triggered the event detect algorithm at TAM and regional events that were identified in records that were triggered by causes other than the regional events. This distinction is important statistically since the frequency of regional events that would trigger the event detect algorithm is counted over the total number of days of station operation whereas the frequency of regional events found buried in records triggered by other causes is counted over the total number of recorded hours of data.

This consideration means that the seismicity rate for near-regional events greater than about $1.8-2.3$ is once every 2.5 years or so. The seismicity rate for detectable near-regional events less than about $1.8-2.3$ is around 16 events/year.

The absence of identified events at mid-regional distance, covering a region entirely within the central saharan shield, suggests that events large enough to trigger the TAM event detect algorithm are relatively rare, probably occurring less than once every five years. Far-regional seismicity can best be determined using TAM in conjunction with other stations and is not a goal of this study.

\section{Comparison with the Sonseca, Spain Array}

The complete lack of events between about $100 \mathrm{~km}$ and $1000 \mathrm{~km}$ from TAM makes it doubtful that a detectability curve, using the procedure of Taylor [3], can be reasonably determined. Rather, some indication of detectability at TAM- for events in the region of the selected event set- will be established by comparison to a known 
seismic station in Sonseca, Spain. Three events were chosen that had nearly equal path lengths to TAM and to the Sonseca, Spain seismic array. Two of the events were nearly co-located in west central Tunisia, about $1300 \mathrm{~km}$ from TAM and Sonseca. The third event was located in the southern Mediterranean ocean off the east coast of Tunisia, some $1500 \mathrm{~km}$ from TAM and Sonseca.

Peak-to-peak signal-to-noise ratios were determined for each event at each station using the Pn phase and the pre-event noise. Only the central station of the Sonseca seismic array was used in this study. All waveforms were narrow bandpass filtered between 1 and $2 \mathrm{~Hz}$. The table below shows the results:

\begin{tabular}{|c|c|c|c|c|}
\hline Event & Location & Magnitude & S/N - TAM & S/N - Sonseca \\
\hline \hline 92164191643 & Tunisia & 5.3 & 225 & 21 \\
\hline 92171180536 & Tunisia & 4.2 & 13 & not detected \\
\hline 93253153947 & South Med. & 4.7 & 15 & not detected \\
\hline
\end{tabular}

The $\mathrm{S} / \mathrm{N}$ for the magnitude 5.3 event is an order of magnitude higher at TAM and the two smaller events were not even detected at Sonseca although they were detected with a reasonably good S/N at TAM. These results, of course, are in large part due to the different paths to the respective stations. The path to TAM for these events is primarily through the central saharan precambrian shield with relatively simple structure and low seismic attenuation. The path to Sonseca is mostly through the southern Mediterranean ocean, with complex geologic structure and high seismic attenuation.

The important point of this comparison is that, from a treaty monitoring perspective, a central saharan monitoring station will have superior detectability for events in some North African countries of concern.

\section{Conclusion}

The short time period that this data set encompasses means that the seismicity rates given should be taken as a very rough estimate. The main point is that near regional and, in particular, mid-regional seismic events are infrequent, even at low magni- 
tudes. The result is consistent with teleseismic observations of low seismicity in the central Saharan shield at higher magnitudes. A verification quality seismic station or array located in the central Saharan shield region should be very useful since it is in an area of monitoring interest, has few regional earthquakes to contend with, is within a large geological province with good regional phase propagation characteristics, and, at least for some events in North Africa and the southern Mediterranean, has a superior detectability compared to some stations at comparable source distances but with paths through the Mediterranean ocean.

\section{Acknowledgments}

Thanks to Dave Harris and Bill Walter for useful discussions and input. We are indebted to the French Institute de Physique de Globe under the auspices of the GEOSCOPE program for supplying the TAM station data and to the Air Force Technical Applications Center for supplying the Sonseca data used in this report.

\section{$\underline{\text { References }}$}

[1] Genik, G.J. (1992), Regional Framework, Structural and Peroleum Aspects of Rift Basins in Niger, Chad and the Central African Republic, Tectonophysics, 213, pp. 169-185.

[2] Wilburn, D.R., J.A. Russell, D.I. Bleiwas, F.E. Heuze (1995), Estimated Use of Explosives in the Mining Industries of Algeria, Iran, Iraq, and Libya, Lawrence Livermore National Laboratory Pub. UCRL-CR-122186.

[3] Taylor, S.R. and H.E. Hartse (1996), Regional Phase Seismic Detection Thresholds at WMQ, Los Alamos National Laboratory Pub. LAUR-96-395. 


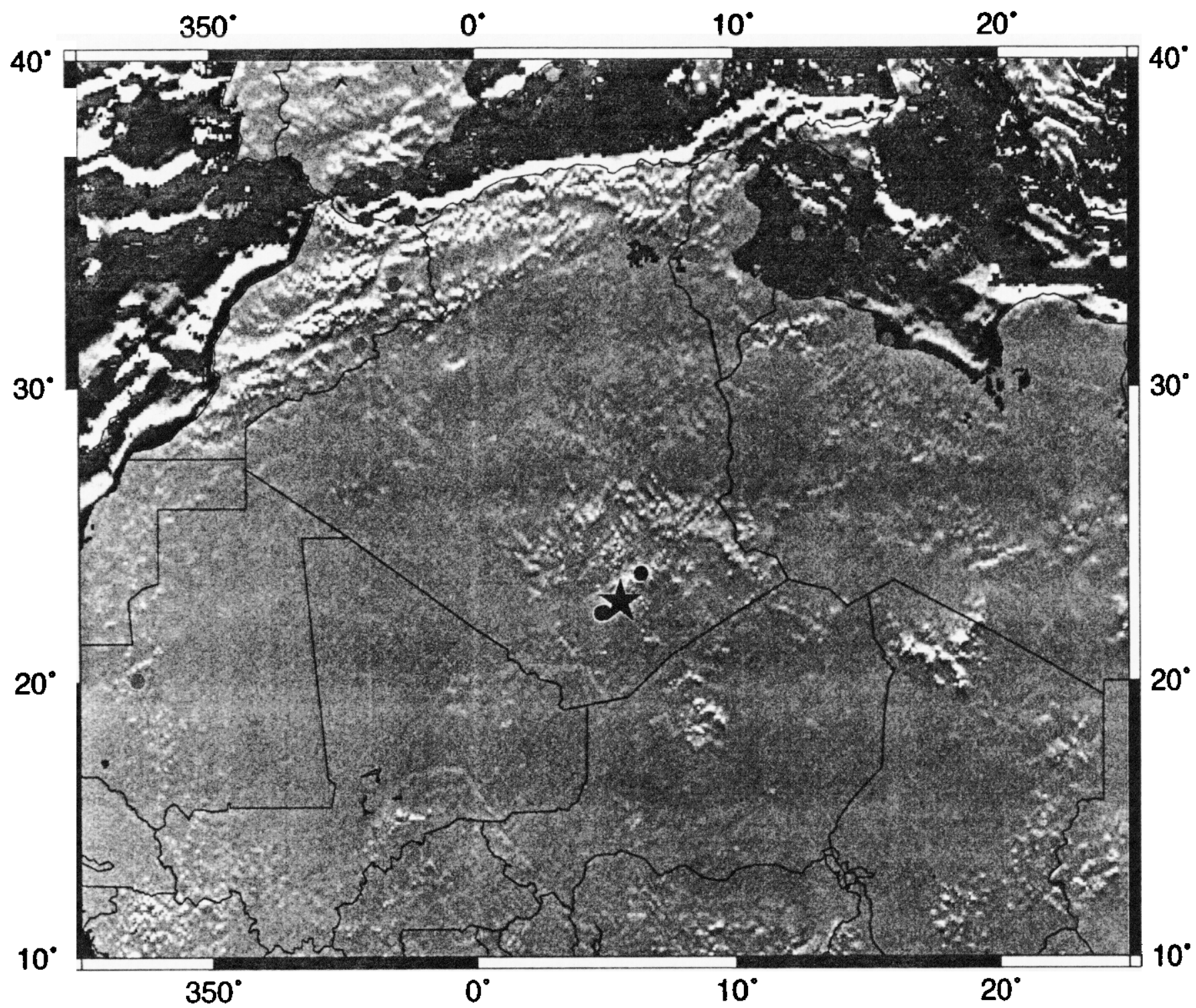

Figure 1: Regional event locations for the TAM data set. TAM station is shown by the red star. The green circles show events located by association, the blue circles show events located by back azimuth and S-P times. 


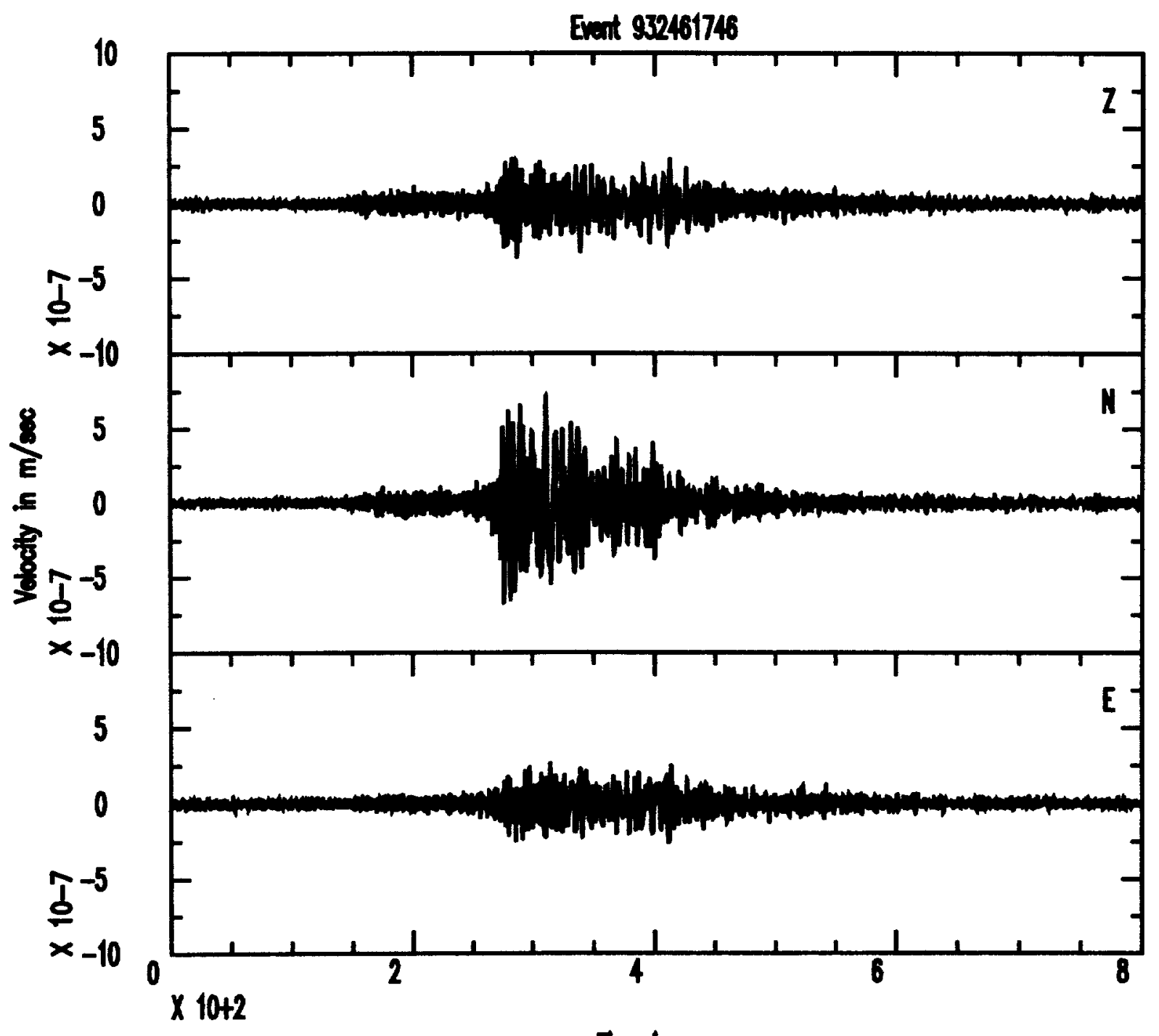

Time h $x$

Figure 2: An isolated far regional event located in Mauritania, some $1925 \mathrm{~km}$ from TAM with a 4.6 body wave magnitude. 

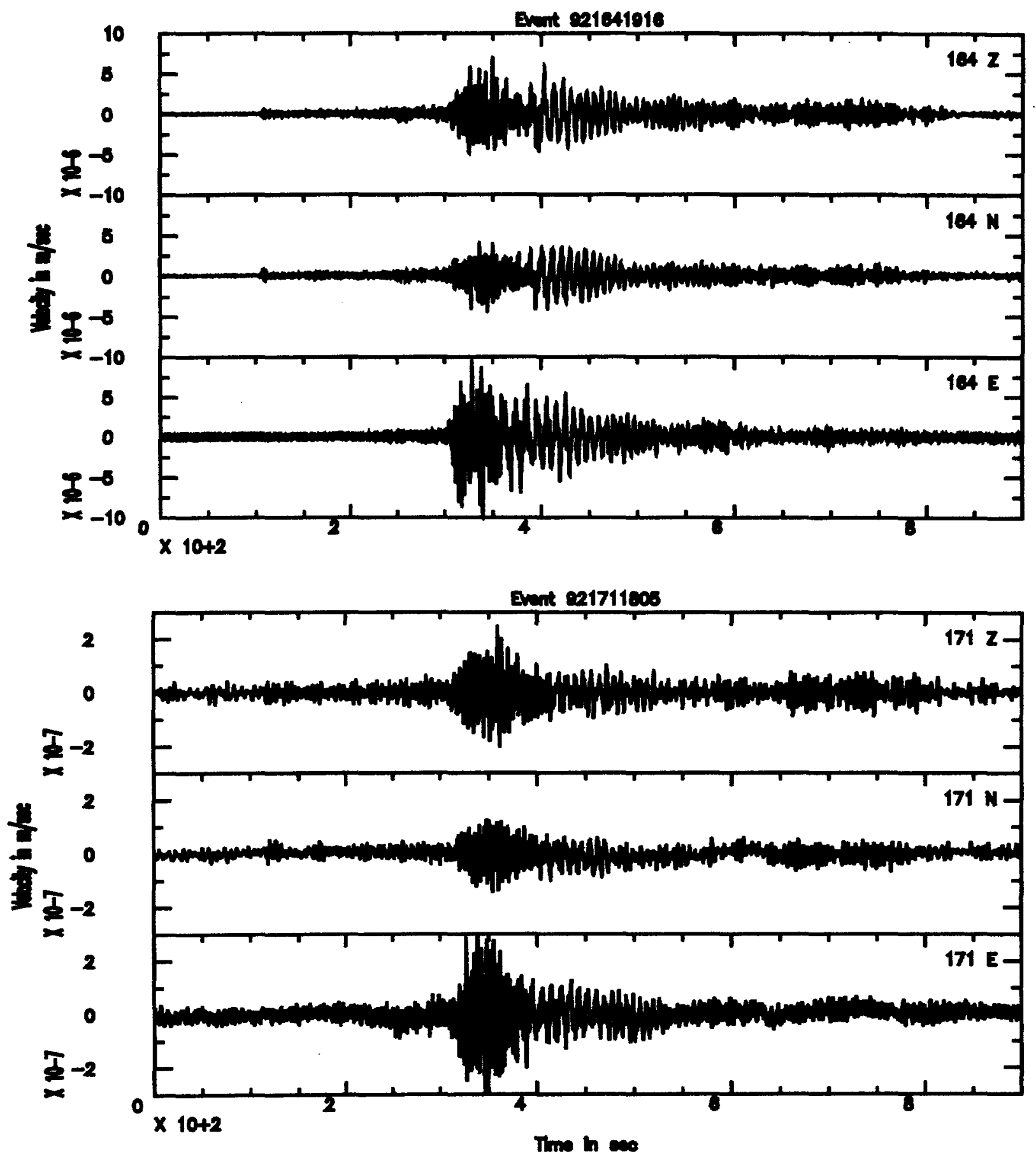

Figure 3: Two events in Tunisia with epicenters about $25 \mathrm{~km}$ apart. The top event has a body wave magnitude of 5.3. The bottom event, possibly associated with the former, has a 4.2 body wave magnitude. The events are about $1300 \mathrm{~km}$ from TAM. 

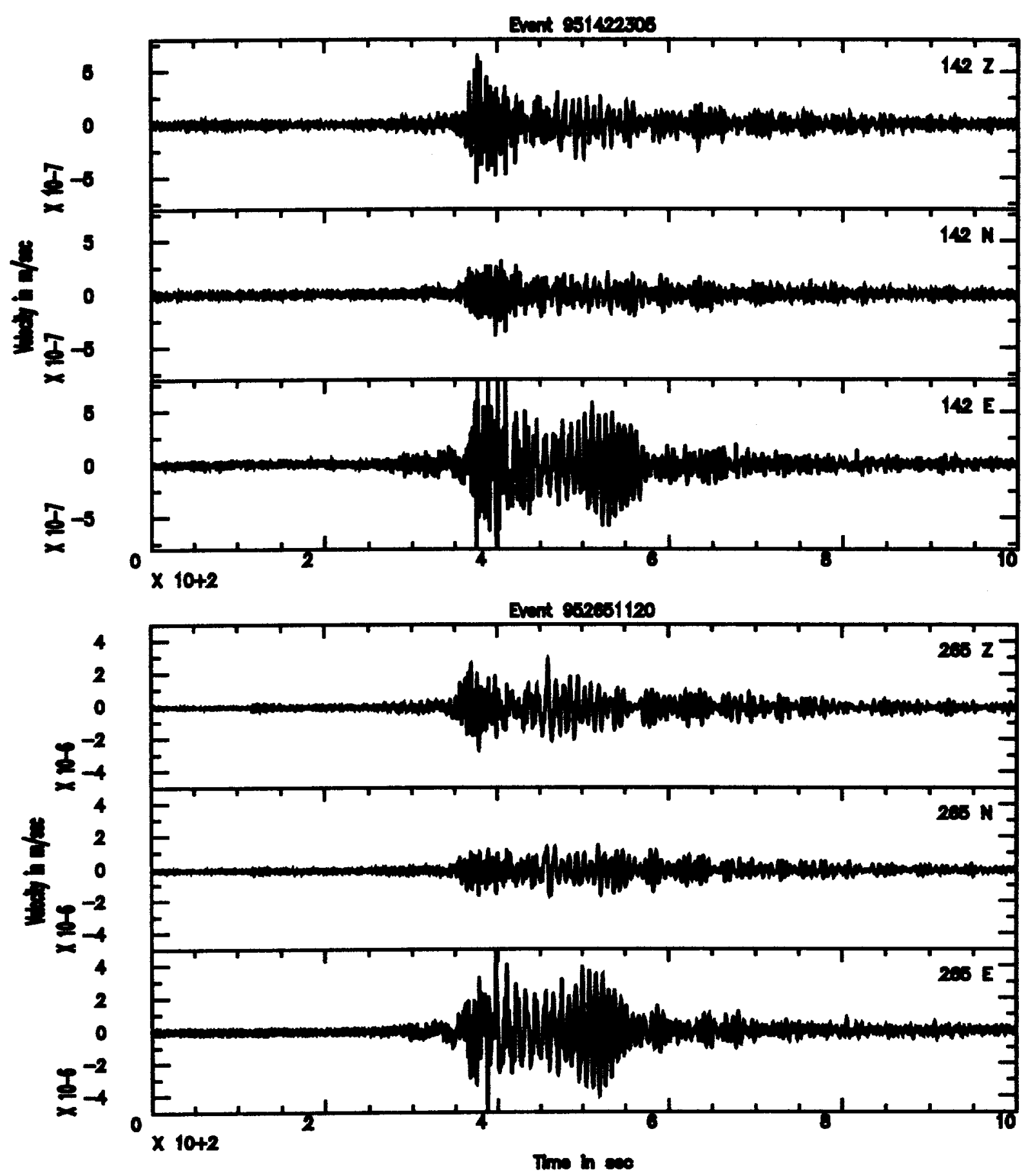

Figure 4: Two events on the Algeria-Tunisia border located about $20 \mathrm{~km}$ apart. The events are about $1400 \mathrm{~km}$ from the TAM station. The top event has a body wave magnitude of 4.1 , the bottom magnitude is 4.7 . 

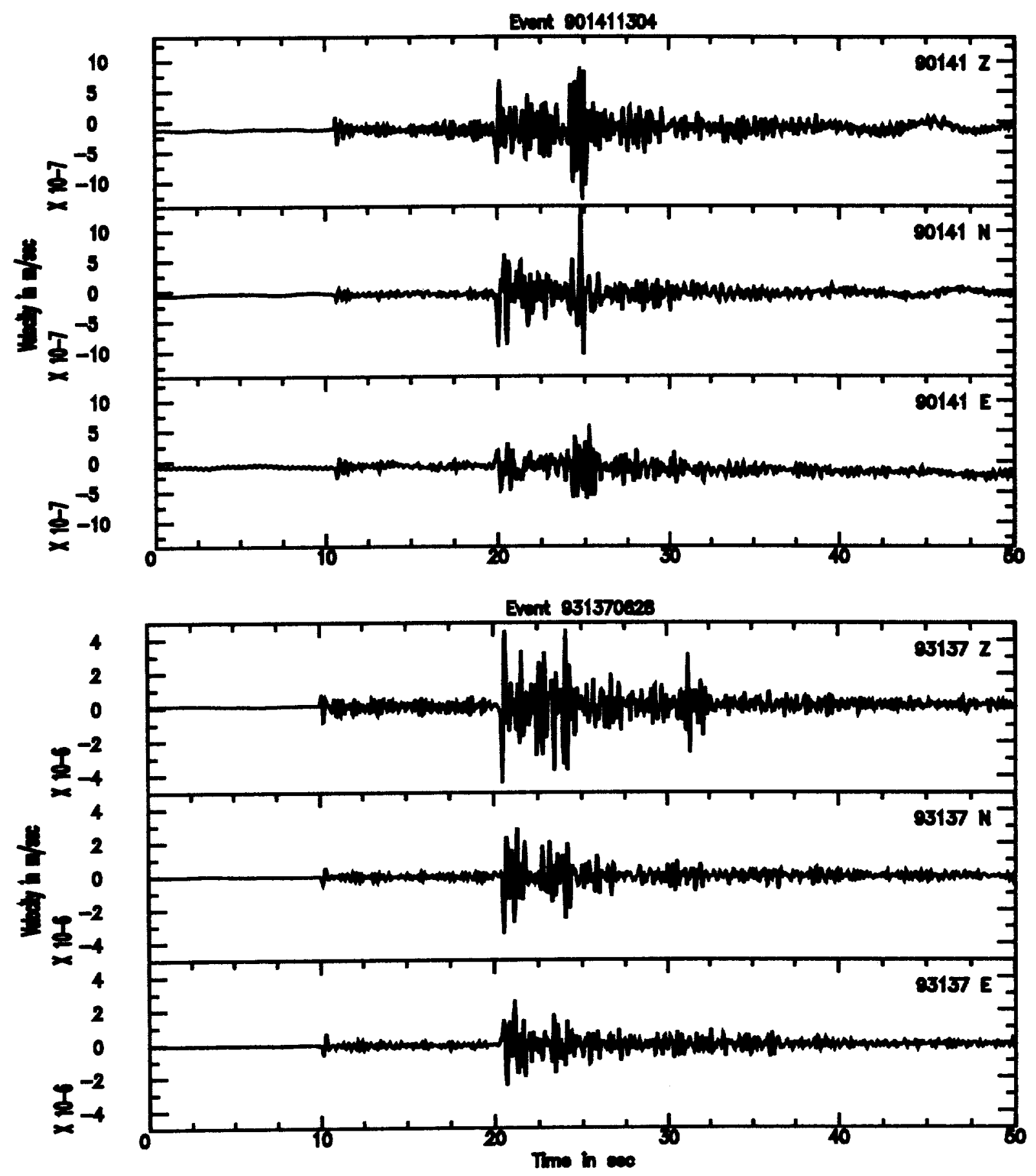

Figure 5: Two near-regional events that triggered the TAM event detect algorithm. These events were located about $100 \mathrm{~km}$ from TAM. 

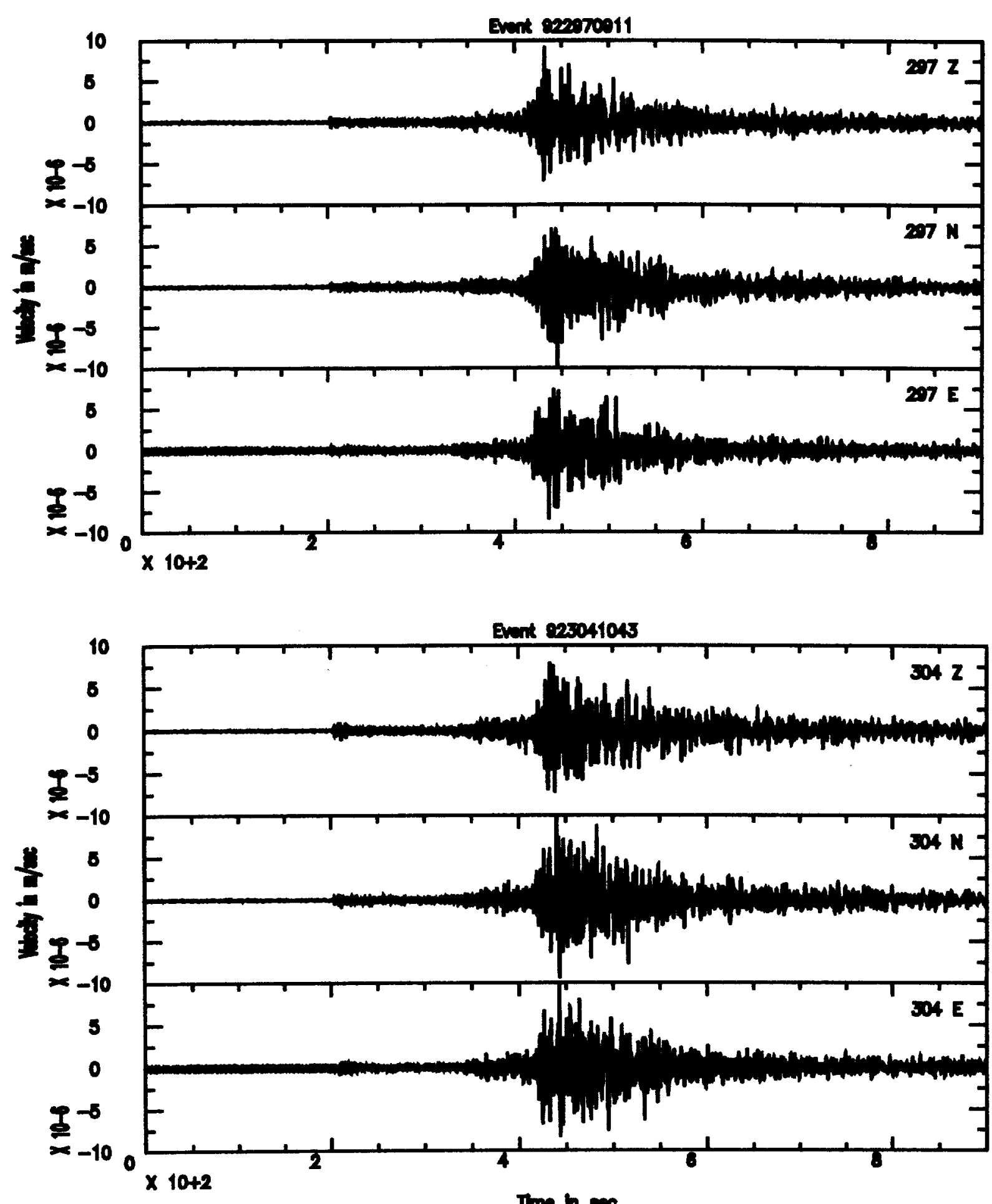

Figure 6: Two nearly co-located events of similar magnitude originating in eastern Morocco near the Algerian border. The body wave magnitudes are 5.3 and 5.1 for the top and bottom event respectively. 


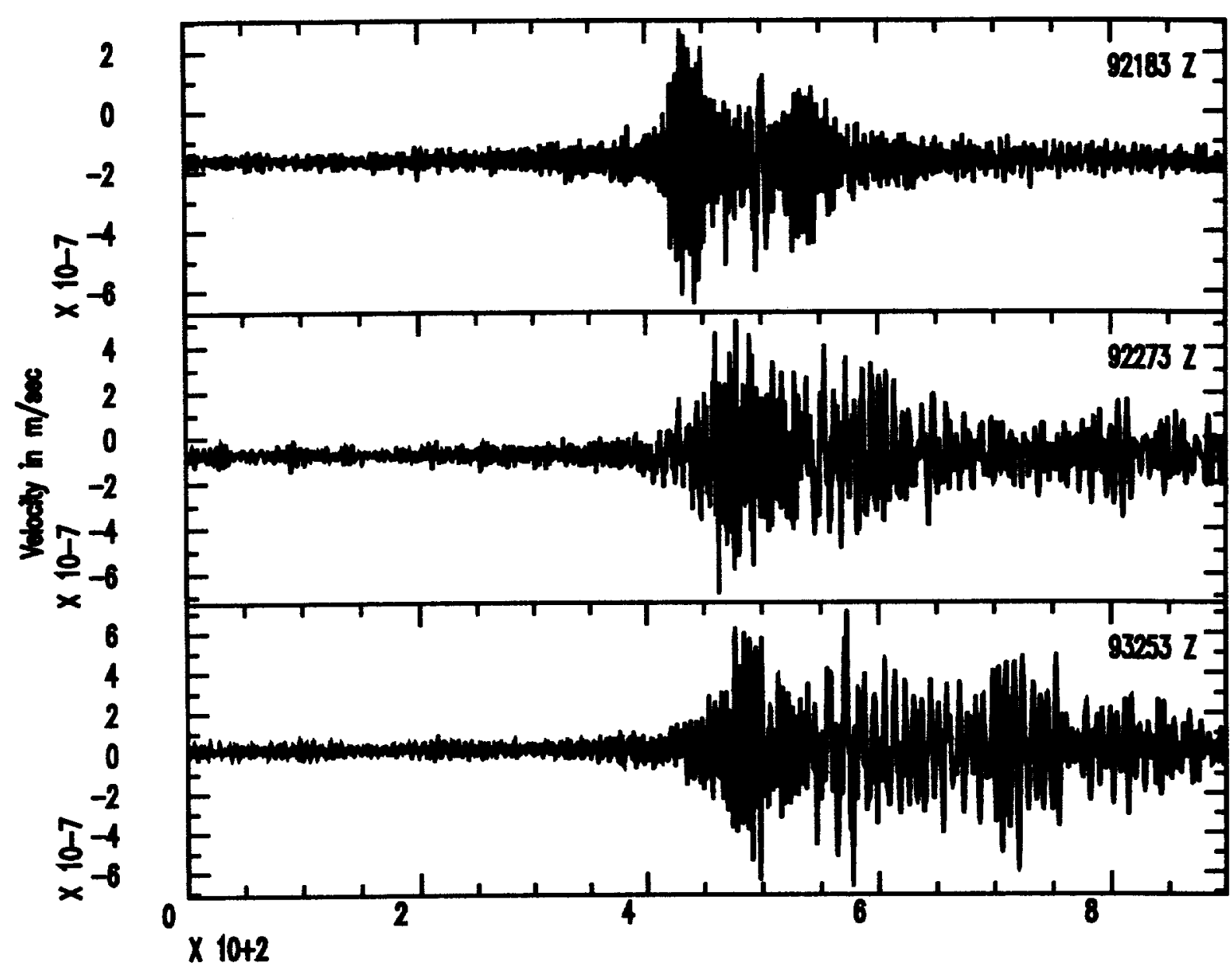

Trme hes

Figure 7: The vertical component recording for three events. The top event is located just off the northwest coast of Libya at body wave magnitude 4.3. The bottom two events are located in the Mediterranean Sea well north of the far western coastline of Libya. The magnitudes for the middle and bottom plot are both 4.7. 

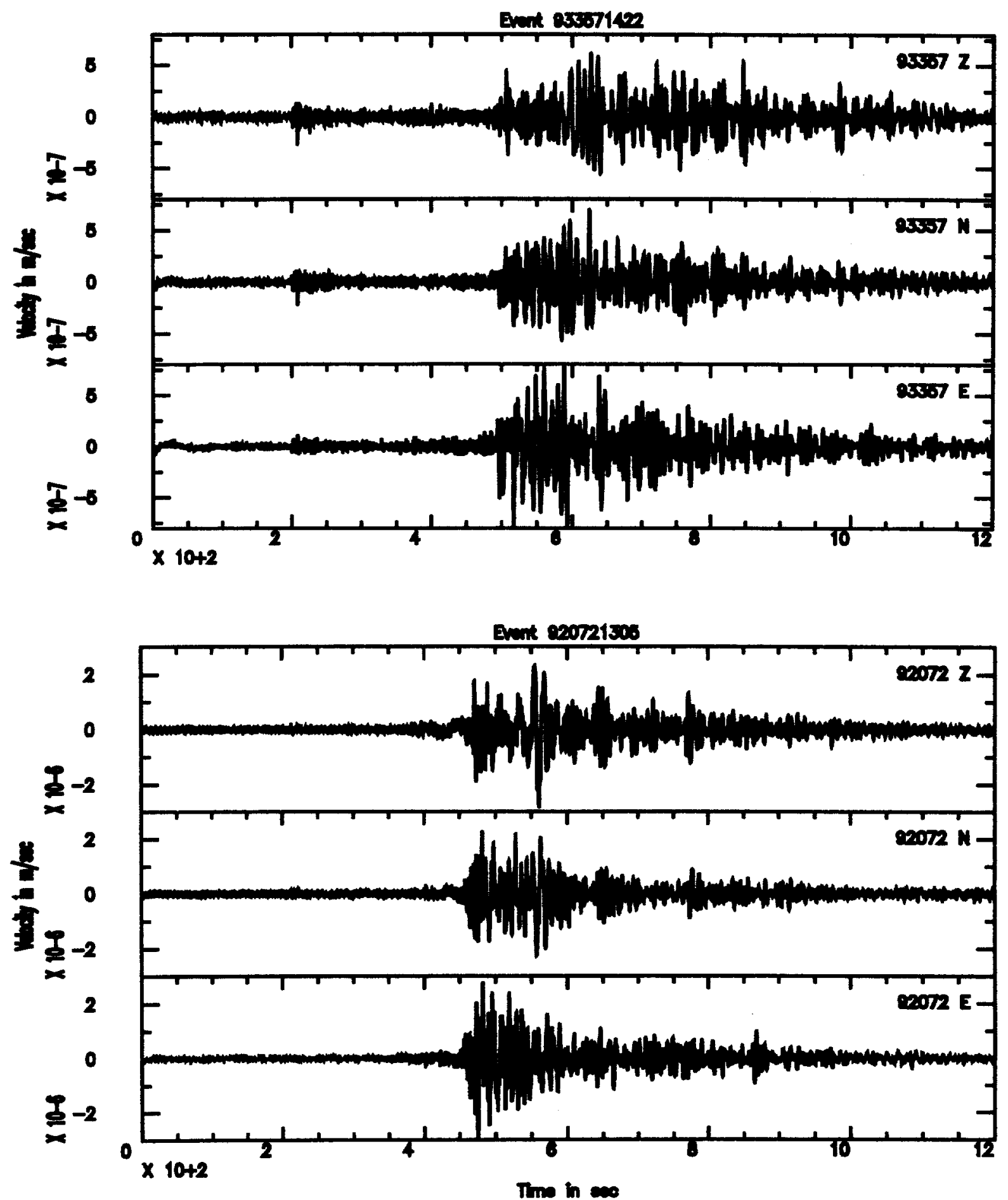

Figure 8: Two events with a similar path to TAM. The top event is a 5.0 event located on the southern coast of Spain. The bottom event is a 5.3 event located just off the northern coast of Morocco. 

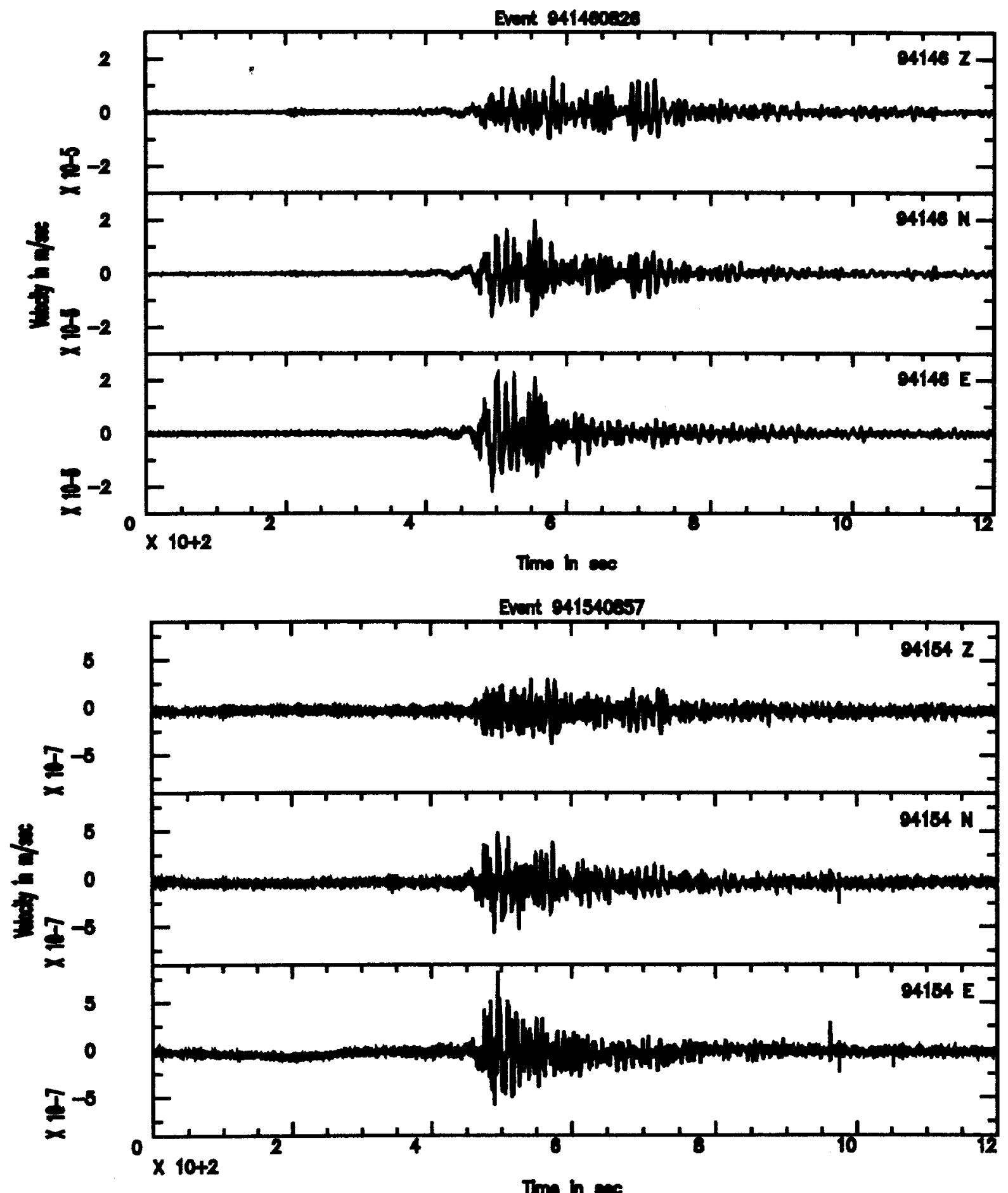

Figure 9: Two events nearly co-located on the north coast of Morocco. The top event has a body wave magnitude of 5.7 . The bottom event has a body wave magnitude of 4.6 


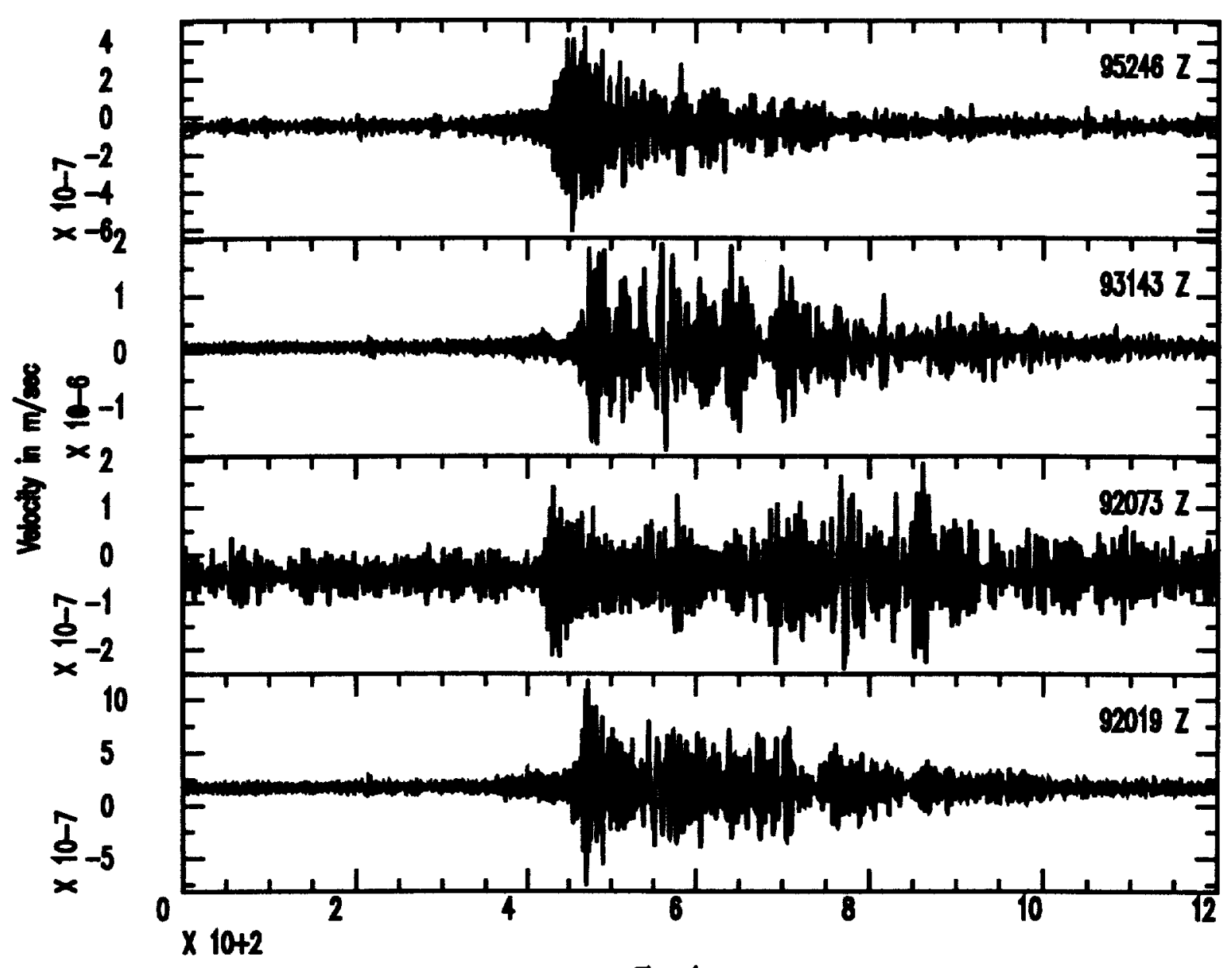

Tim h

Figure 10: Vertical component recordings from four events. The top 4.1 event was located in the Atlas mountians of Morocco. The next event, 93143, with magnitude 5.4, was located on the south coast of Spain. The third event down, 92073, was located on the north coast of Morocco near the Algerian border with magnitude 4.3. The bottom event, with magnitude 4.7, was located near the north coast of Algeria. 


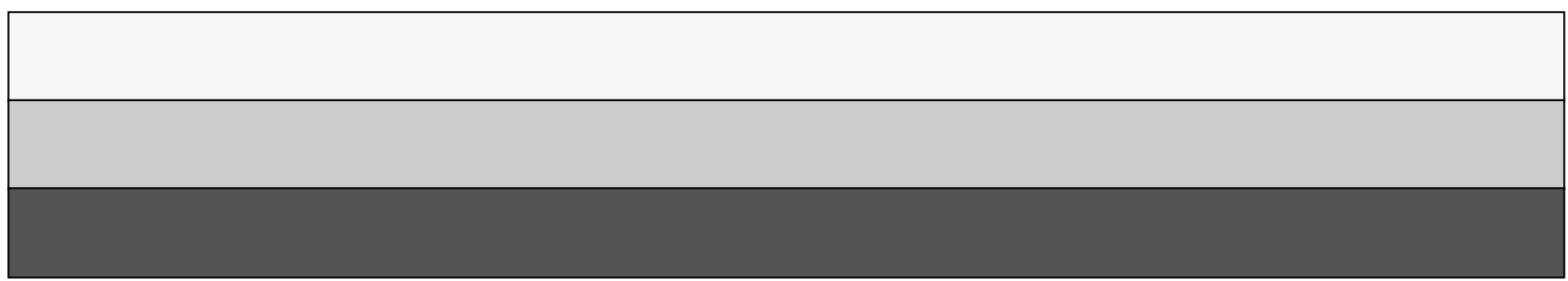

